\title{
Derecho colectivo del trabajo en Argentina: Un modelo a considerar en Chile
}

\author{
Claudia Rodrigo Silva*
}

\begin{abstract}
RESUMEN
El presente análisis tiene por objeto realizar una revisión de las principales instituciones que rigen el Derecho Colectivo del Trabajo de Argentina, entregando elementos que permitan comparar esta regulación con aquella que norma el Derecho Colectivo del Trabajo en Chile. Se toma como punto de partida el nivel de ejercicio de los derechos fundamentales colectivos del trabajo en ambos países, y se desarrolla el análisis mediante la pesquisa de la normativa argentina, interpretando críticamente los resultados, y determinando los modelos de leyes que están influyendo en los diferentes niveles de ejercicio de estos derechos en Argentina y Chile.
\end{abstract}

Derecho Colectivo del Trabajo de Argentina - sindicación - negociación colectiva

\section{Collective bargain labour law in Argentina: A model to consider in Chile}

\begin{abstract}
The article conducts a review of the main institutions governing collective bargain labour law in Argentina, drawing comparisons with its regulation in Chile. It takes as its starting point the exercise of fundamental rights of workers in both countries. It develops the analysis of the Argentinean legislation, critically interpreting the results and presenting some conclusions about the model laws that are influencing how these rights are exercised at different levels in Argentina and Chile.
\end{abstract}

Argentinean collective bargain labour law - Unionization - collective bargaining

* Licenciada en Ciencias Jurídicas y Sociales, Universidad de Chile. Correo electrónico: claudiarodrigos@yahoo.es

Artículo recibido el 30 de agosto de 2012 y aceptado para su publicación por el Comité Editorial el 29 de mayo de 2013. 


\section{INTRODUCCIÓN}

A rgentina se caracteriza por ser uno de los países de Latinoamérica con una legislación proteccionista de los Derechos Fundamentales Colectivos del Trabajo. En Chile no ocurre lo mismo. El Derecho Colectivo del Trabajo se encuentra en exceso regulado y restringido.

Por un lado, en Argentina nos encontramos con una normativa cuyos orígenes se remontan a los gobiernos de Perón y de Alfonsín, con algunos resabios de leyes promulgadas durante los gobiernos de Menem y De la Rúa. Por el otro, en Chile debemos remontarnos a la dictadura de Pinochet, y a las reformas neoliberales implementadas en materia laboral en el año 1978, conocidas como el "Plan Laboral".

Los órganos de control ${ }^{1}$ de la OIT han realizado diversas recomendaciones al Estado de Chile para que modifique su legislación en relación con ciertas instituciones atentatorias de la libertad sindical, relativas tanto con la negociación colectiva como con el derecho de huelga, y el Estado ha hecho poco al respecto.

En cuanto al ejercicio de estos derechos, en Argentina se realiza de manera permanente por amplios sectores de trabajadores, mientras que en Chile su ejercicio es muy limitado.

Frente a este problema, la doctrina laboralista ${ }^{2}$ chilena ha realizado quizás las principales críticas al modelo de Derecho Colectivo del Trabajo vigente actualmente, y asimismo se ha hecho desde centros de investigación de algunas universidades del país.

Sin embargo, no se ha realizado un análisis comparativo de este modelo con uno de los modelos más protectores en la materia, como lo es el Derecho Colectivo del Trabajo de Argentina. Y precisamente porque se trata de Derechos Fundamentales, consagrados en diversos instrumentos internacionales de Derechos Humanos ${ }^{3}$, tomando como punto de partida la necesidad que dentro del ordenamiento jurídico se respeten y promuevan los Derechos Fundamentales Colectivos de los trabajadores, es que consideramos gravitante analizar los factores normativos que pueden estar influyendo en las diferencias entre ambos países.

El objetivo del artículo es realizar un análisis de las principales instituciones del Derecho Colectivo del Trabajo de Argentina, entregando elementos que permitan analizar comparativamente e interpretar críticamente el Derecho Colectivo del Trabajo en

${ }^{1}$ Tanto el Comité de Libertad Sindical como la Comisión de Expertos en la Aplicación de Convenios y Recomendaciones.

${ }^{2}$ Ver Caamaño, E. y Ugarte, J. L., Negociación Colectiva y Libertad Sindical. Un enfoque crítico, Santiago de Chile, Legalpublishing, 2008, Negociación Colectiva en Chile: la debilidad de un derecho imprescindible, División de Estudios, Dirección del Trabajo, 2009, y el Informe anual sobre Derechos Humanos en Chile 2008, Santiago de Chile, Universidad Diego Portales, 2008.

${ }^{3}$ Así, en la Declaración Universal de Derechos Humanos, en la Declaración Americana de los Derechos y Deberes del Hombre, en el Pacto Internacional de Derechos Civiles y Políticos, en el Pacto de Derechos Económicos, Sociales y Culturales, en la Declaración Relativa a los Principios y Derechos Fundamentales en el Trabajo de la OIT de 1998, además de los convenios de la OIT, entre ellos, el Convenio 154 sobre fomento a la Negociación Colectiva, y los Convenios 87 y 98, sobre Libertad Sindical y Negociación Colectiva, respectivamente. 
Chile. Para ello se realiza una revisión documental extensa, que incluye datos empíricos -elaborados por el Ministerio del Trabajo, Empleo y Seguridad Social de la República Argentina (MTEySS), y la Encuesta Nacional de Condiciones Laborales 2008 de Chile-, y la revisión de la normativa argentina.

\section{EjERCICIO DE LOS DERECHOS COLECTIVOS DEL TRABAjO en Argentina y Chile: algunas cifras relevantes}

Primeramente, antes de iniciar la revisión en el terreno normativo, es necesario constatar que Argentina es uno de los países con mayores índices de ejercicio de los derechos colectivos del trabajo en Latinoamérica, abarcando sectores importantes de la población asalariada. De acuerdo con los datos arrojados por el Boletín de Estadísticas Laborales del MTEySS ${ }^{4}$ de 2011 de la República Argentina, de los cerca de 15 millones de trabajadores que tiene el país, el 37\% de ellos tiene afiliación sindical, y el $83 \%$ regula sus remuneraciones y condiciones de trabajo mediante convenios colectivos. Solo en el año 2011 se realizaron 1.864 negociaciones, que involucraron a 4.235 .000 habitantes.

En Chile en cambio, el ejercicio de estos derechos es, a todas luces, muy bajo. En el año 2008 el 11,9\% de los trabajadores tenía afiliación sindical, el 9,2\% había negociado colectivamente, y tan solo el $1 \%$ había ejercido su derecho a huelga, de acuerdo con los datos arrojados por la Encuesta Nacional de Condiciones Laborales $2008^{5}$.

Los factores que explican estas diferencias en el comportamiento colectivo de los trabajadores de ambos países son variados. Los hay de tipo sociocultutral, histórico, político, y como reflejo de los mismos, normativos. Sin embargo, considerando que la realidad y la norma interactúan dialécticamente, esta puede influir en aquella, en una u otra dirección determinada. Y en ese sentido es que estimamos relevante estudiar la normativa de un país que en ciertos ámbitos como el ejercicio de los derechos fundamentales colectivos de los trabajadores nos puede servir de modelo, en algunos aspectos al menos.

\section{El Derecho Colectivo del Trabajo en Chile, en pocas palabras}

Previo al estudio de las principales instituciones del modelo argentino de Derecho Colectivo del Trabajo, constatamos que el modelo de Derecho Colectivo del Trabajo en Chile es ultrarrestrictivo, y, tomando como referencia los pilares del Derecho Colectivo del $\operatorname{Trabajo}^{6}$, está basado en las siguientes instituciones principales: sindicación vinculante exclusivamente a nivel de empresa, negociación colectiva vinculante únicamente a nivel de empresa, exclusión de negociación colectiva reglada a diversos sectores, excesiva

\footnotetext{
${ }^{4}$ Disponible en www.trabajo.gov.ar

${ }^{5}$ Disponible en www.dt.gob.cl

${ }^{6}$ Ermida, O. citado en Caamaño, E. y Ugarte, J. L., Negociación Colectiva y Libertad Sindical. Un enfoque crítico, Santiago de Chile, Legalpublishing, 2008, p. 51.
} 
reglamentación de la huelga -contemplándose únicamente cono última etapa del procedimiento de negociación colectiva reglada-, prohibición de ejercer la huelga a diversos sectores, el "reemplazo de trabajadores en huelga" y, vale destacar, tipifica además el delito de huelga para ciertos casos que establece la Ley $\mathrm{N}^{\circ} 12.927$ de Seguridad del Estado.

Este modelo ha sido criticado por la doctrina laboralista de avanzada, así como por el Informe Anual de Derechos Humanos que publica la Universidad Diego Portales en reiteradas ocasiones. En definitiva, bastante se ha escrito ya sobre eso. Por ello es que el análisis se basa en la revisión de un modelo opuesto: el modelo argentino.

\title{
III. El Derecho Colectivo del Trabajo en Argentina: Constitución Nacional de la República Argentina, artículo i 4 BIS
}

Incorporado a la Constitución Nacional mediante la reforma constitucional del año 1957, consagra una serie de derechos del trabajo, tanto a nivel individual y colectivo como de la seguridad social. En el ámbito que nos convoca se garantiza el derecho de sindicación, de negociación colectiva, y el derecho a huelga, en los siguientes términos:

\begin{abstract}
El trabajo en sus diversas formas gozará de la protección de las leyes, las que asegurarán al trabajador: ... organización sindical libre y democrática, reconocida por la simple inscripción en un registro especial.

Queda garantizado a los gremios: concertar convenios colectivos de trabajo; recurrir a la conciliación y al arbitraje; el derecho de huelga. Los representantes gremiales gozarán de las garantías necesarias para el cumplimiento de su gestión sindical y las relacionadas con la estabilidad de su empleo.
\end{abstract}

Resulta fundamental esta disposición constitucional, ya que se está garantizando, como se ha dicho, los tres pilares indispensables e interdependientes sobre los cuales descansa la libertad sindical: el sindicato, la negociación colectiva, y la huelga ${ }^{7}$.

La norma está redactada en términos amplios, lo que favorece la autonomía sindical. En cuanto a la huelga, al no estar determinada su finalidad, se dejan muchas posibilidades de ejercer este derecho. En doctrina, corresponde al denominado modelo autónomo de huelga. Se trata de aquellos órdenes jurídicos más respetuosos de la autonomía colectiva, que dejan a los actores sindicales determinar cuál será el objetivo de la buelga respectiva ${ }^{8}$. Por ejemplo, podría realizarse una huelga de solidaridad, o en defensa de sus condiciones de vida o de su seguridad social.

Recordemos que en Chile, si bien está reconocido en la Constitución Política de la República el derecho de sindicación y la negociación colectiva -artículo $19 \mathrm{n}^{\circ} 16 \mathrm{y}$ $\mathrm{n}^{\circ} 19$, respectivamente-, no existe una consagración expresa del derecho a huelga. Se

\footnotetext{
${ }^{7}$ Íbid.

${ }^{8}$ Caamaño, E. y Ugarte, J.L., ob. cit., p. 82.
} 
establece por vía de las limitaciones, mencionando los sectores de trabajadores a quienes les está prohibido declarar la huelga?

Por último, destacar que la norma en comento, en su inciso tercero, que garantiza la seguridad social ${ }^{10}$, lo hace en términos amplios, consagrando entre otros el derecho a una vivienda digna. Estimamos que es de suma relevancia esta cuestión, ya que de acuerdo con la Ley $\mathrm{N}^{\circ} 23.551$ de Asociaciones de Trabajadores, sería posible ejercer algún tipo de medidas dentro de su programa de acción, por vulneración de este derecho, así como de cualquier otro derecho que tenga relación con las condiciones de vida y de trabajo.

\section{Derecho Internacional del Trabajo en la Constitución Nacional de la República Argentina}

La norma contenida en el artículo 75 numeral 22 de la Constitución Nacional de la República Argentina, determina el rango que tendrán los tratados, concediéndoseles una jerarquía superior a las leyes. Se menciona una serie de tratados de Derechos Humanos que tienen rango constitucional, y se establece que los restantes tratados de Derechos Humanos - los que no han sido mencionados en dicha norma- deberán cumplir con un cierto cuórum de aprobación para gozar de rango constitucional ${ }^{11}$.

Existe consenso en su interpretación, en el sentido que los tratados de Derechos Humanos se incorporan a la legislación nacional una vez ratificados, sin necesidad de dictarse una norma especial. Y tampoco existe discusión en relación con la naturaleza jurídica de Derechos Fundamentales que tienen los derechos colectivos del trabajo.

\footnotetext{
${ }^{9}$ La doctrina laboralista mayoritaria en Chile ha sostenido que el derecho a huelga ha sido reconocido como una garantía constitucional implícita, reconocido tácitamente.

${ }^{10}$ Dicho inciso establece: "El Estado otorgará los beneficios de la seguridad social, que tendrá carácter de integral e irrenunciable. En especial, la ley establecerá: el seguro social obligatorio, que estará a cargo de entidades nacionales o provinciales con autonomía financiera y económica, administradas por los interesados con participación del Estado, sin que pueda existir superposición de aportes; jubilaciones y pensiones móviles; la protección integral de la familia; la defensa del bien de familia; la compensación económica familiar y el acceso a una vivienda digna".

${ }^{11}$ Art. 75: "Corresponde al Congreso: 22. Aprobar o desechar tratados concluidos con las demás naciones y con las organizaciones internacionales y los concordatos con la Santa Sede. Los tratados y concordatos tienen jerarquía superior a las leyes.

La Declaración Americana de los Derechos y Deberes del Hombre; la Declaración Universal de Derechos Humanos; la Convención Americana sobre Derechos Humanos; el Pacto Internacional de Derechos Económicos, Sociales y Culturales; el Pacto Internacional de Derechos Civiles y Políticos y su Protocolo Facultativo; la Convención Sobre la Prevención y la Sanción del Delito de Genocidio; la Convención Internacional sobre la Eliminación de Todas las Formas de Discriminación Racial; la Convención Sobre la Eliminación de Todas las Formas de Discriminación Contra la Mujer; la Convención Contra la Tortura y Otros Tratos o Penas Crueles, Inhumanos o Degradantes; la Convención Sobre los Derechos del Niño; en las condiciones de su vigencia, tienen jerarquía constitucional, no derogan artículo alguno de la primera parte de esta Constitución y deben entenderse complementarios de los derechos y garantías por ella reconocidos. Solo podrán ser denunciados, en su caso, por el Poder Ejecutivo Nacional, previa aprobación de las dos terceras partes de la totalidad de los miembros de cada Cámara.

Los demás tratados y convenciones sobre derechos humanos, luego de ser aprobados por el Congreso, requerirán el voto de las dos terceras partes de la totalidad de los miembros de cada Cámara para gozar de la jerarquía constitucional".
} 
En efecto, están consagrados en diversos instrumentos internacionales sobre Derechos Humanos ${ }^{12}$.

Es importante destacar que tratándose de normativa internacional sobre Derechos Humanos, tiene cabida el sistema que la doctrina ha denominado monista, en el cual el derecho interno y el derecho internacional se tienen como integrantes de la misma esfera jurídica, $y$ donde, como consecuencia, los tratados ratificados son parte integral del derecho nacional ${ }^{13}$, en contraposición al sistema dualista, en que es necesario que una norma de derecho interno incorpore el contenido de la normativa internacional que ha sido ratificada por el Estado, como es el sistema que opera en Chile.

Y en materia de Derecho Colectivo del Trabajo, Argentina ha ratificado los Convenios de la OIT sobre libertad sindical y promoción del derecho de sindicación $\left(\mathrm{N}^{\circ} 87\right)$, Convenio sobre la aplicación de los principios del derecho de sindicación y de negociación colectiva ( $\left.\mathrm{N}^{\circ} 98\right)$, Convenio sobre la consulta tripartita ( $\left.\mathrm{N}^{\circ} 144\right)$, Convenio sobre protección del derecho de sindicación y los procedimientos para determinar las relaciones de trabajo en la administración pública $\left(\mathrm{N}^{\circ} 151\right)$, Convenio sobre fomento a la negociación colectiva ( $\left.\mathrm{N}^{\circ} 154\right)$, y el Convenio sobre la protección y facilidades que deben otorgarse en la empresa a los representantes de los trabajadores ( $\left.\mathrm{N}^{\circ} 135\right)$.

De acuerdo con Simón, juez nacional de la Cámara de Apelaciones del Trabajo de la República Argentina, en función de lo normado por el artículo $5^{\circ}$ del Tratado de Viena sobre Derecho de los Convenios (sic) no existe duda alguna respecto del carácter de Tratados respecto de los Convenios de la OIT ${ }^{14}$.

En consecuencia -y en armonía con el sistema monista-, un juez nacional podría utilizar esta fuente de derecho -los Convenios de la OIT, y los tratados de Derechos Humanos en general- en diversos sentidos ${ }^{15}$.

En primer término, podría utilizarse para resolver directamente un litigio, siempre que se trate de una norma internacional que posea el self executing o autoejecutable, en el sentido de ser lo suficientemente clara y precisa como para reconocer derechos directamente exigibles ante los tribunales ${ }^{16}$, ya sea para llenar una laguna del derecho nacional, para descartar una disposición del derecho nacional menos favorable para los trabajadores, o bien, para invalidar una disposición de derecho interno. Luego, podría utilizarse en una función interpretativa del Derecho Internacional del Trabajo: para resolver ambigüedades del derecho interno, o para interpretar un texto redactado en términos generales, o para evaluar la constitucionalidad de una disposición de derecho nacional. También podría el juez utilizar el Derecho Internacional del Trabajo como fuente de inspiración de

12 Enunciados en la nota al pie de página $n^{\circ} 4$.

13 Beaudonnet, X., Derecho internacional del trabajo y derecho interno, Manual de formación para jueces, juristas y docentes en derecho, Centro Internacional de Formación OIT, Turín, Italia, 2010, p. 14.

${ }^{14}$ Simón, J., "Breve informe sobre la negociación colectiva en la República Argentina”, en Revista de Trabajo, Buenos Aires, año 2, no 3, julio-diciembre, 2006, p. 44.

15 A mayor abundamiento, para este tema ver Beaudonnet, X., ob. cit., pp. 17-36.

${ }^{16}$ Beaudonnet, X., ob. cit., p. 21. 
principios jurisprudenciales. Y por último, podría utilizarlo para reforzar una decisión basada en el derecho nacional ${ }^{17}$.

Cabe señalar que Chile en cambio, en materia de Derecho Colectivo del Trabajo, ha ratificado únicamente los Convenios de la OIT $\mathrm{N}^{\circ} 87, \mathrm{~N}^{\circ} 98, \mathrm{~N}^{\circ} 151$ y $\mathrm{N}^{\mathrm{o}} 135$, y el sistema de incorporación de Derecho Internacional es el sistema dualista, que es más restrictivo, ya que para su vigencia se requiere la dictación de una ley posterior ${ }^{18}$.

\section{El Derecho Colectivo del Trabajo en Argentina: normativa legal}

La legislación que regula el Derecho Colectivo del Trabajo está contenida en diversas leyes, no existiendo una sistematización de todas ellas en un cuerpo normativo, como lo es por ejemplo el Código del Trabajo en Chile. Entre ellas, podemos señalar las siguientes leyes: Ley N N $^{\circ} 3.551$ de Asociaciones Sindicales de Trabajadores, Ley No 14.250 de Convenciones Colectivas de Trabajo, Ley N 23.546 sobre Procedimientos de la Negociación Colectiva, Ley $\mathrm{N}^{\circ}$ 14.786, sobre Resolución de Conflictos Colectivos del Trabajo, Ley $\mathrm{N}^{\circ} 25.877$ de Ordenamiento Laboral, Ley $\mathrm{N}^{\circ} 25.674$ sobre Participación Femenina en las Unidades de Negociación, Ley $\mathrm{N}^{\circ} 24.013$ Nacional de Empleo, Ley $\mathrm{N}^{\circ} 23.929$ sobre Convenciones Colectivas de Trabajo en la Administración Pública, Ley No 24.185 sobre Negociación Colectiva para los Trabajadores Docentes, Ley $\mathrm{N}^{\circ} 24.467$ de Pequeñas y Medianas Empresas, y la Ley $\mathrm{N}^{\circ} 23.554$ que ratifica el Convenio $\mathrm{N}^{\circ} 154$ de la OIT sobre Fomento a la Negociación Colectiva.

A continuación revisaremos las siete primeras enunciadas en relación con las principales instituciones que regula esa normativa, dejando fuera del análisis por ahora a los sectores específicos docente y de la administración pública.

\section{A) Ley $N^{o} 23.551$ sobre Asociaciones Sindicales de Trabajadores ${ }^{19}$}

En primer lugar, esta norma, ubicada en el título preliminar referido a la tutela de la libertad sindical, garantiza en términos amplios la libertad sindical. Luego, se señala el objeto de las asociaciones sindicales, cual es la defensa de los intereses de los trabajadores.

Merece la pena detenernos en este punto. La norma define qué es lo que se entenderá por interés de los trabajadores: "todo cuanto se relacione con sus condiciones de vida y de trabajo" ${ }^{20}$. Y en consecuencia, si nos remitimos solo a esta disposición, los trabajadores podrían declarar una huelga, por ejemplo, para defender el derecho a una

17 Íbid.

${ }^{18}$ El Código del Trabajo chileno zanja esta cuestión en relación con el contenido que deberá tener la sentencia, en el artículo $460 \mathrm{n}^{\circ} 5$ del Código del Trabajo, que dispone que ella debe contener Los preceptos constitucionales, legales o los contenidos en tratados internacionales ratificados por Chile y que se encuentren vigentes.

19 Promulgada en el año 1988, durante el gobierno de Raúl Alfonsín.

${ }^{20}$ Artículo $3^{\circ}$. 
vivienda digna - en conformidad a los derechos garantizados en el artículo 14 bis de la Constitución Nacional de la República Argentina-, o como respuesta a una determinada política económica que defina el gobierno de turno, y que afecte sus condiciones de vida, o inclusive, podrían declarar la huelga debido al alza de las tarifas de la locomoción colectiva o del "subte" 21 .

Se estatuye derechos a las asociaciones sindicales, entre los que destacamos el derecho a formular su programa de acción, realizar todas las actividades lícitas en defensa del interés de los trabajadores, el derecho a negociar colectivamente ${ }^{22}$ y a declarar la huelga, y a garantizar una efectiva democracia interna, por medio de diversas normas ${ }^{23}$.

\section{Tipos de asociaciones sindicales}

Primordial es la norma que determina los tipos de asociaciones sindicales, distinguiéndose a asociaciones de trabajadores de un mismo sector, actividad o actividades afines -asociaciones verticales-, trabajadores del mismo oficio, profesión o categoría, aunque se desempeñen en actividades distintas -asociaciones horizontales-, y trabajadores que presten servicios en una misma empresa.

En términos simples, es permitida la unidad de los trabajadores, y más aún, es garantizada constitucionalmente, de acuerdo con la norma del artículo 14 bis ya comentada. En términos jurídicos, esta disposición permite a los trabajadores conformar una organización de centralización intermedia, o centralizada, que represente a amplios sectores. La consecuencia de tener la unidad de los trabajadores -por ejemplo, en una asociación por rama- es determinante a la hora de realizar una negociación con la parte empleadora, debido a que la presión que pueda ejercer la parte trabajadora -y su poder negociador- aumentará al contar con más trabajadores movilizados, teniendo mejores posibilidades para obtener sus reivindicaciones, en defensa de sus condiciones de vida y de trabajo.

En este sentido, se ha dicho que la negociación centralizada a nivel de las actividades económicas, por su parte, tiende a frenar el aumento de la diferenciación salarial entre subramas, empresas, regiones o niveles de calificación, ya que la capacidad de representación del sindicato y su posición de fuerza en la negociación se potencian cuando todos los asalariados de la actividad se benefician en grado similar por los resultados de la negociación, y que en la literatura internacional se ha documentado que existe una relación inversa entre el grado de centralización

${ }^{21}$ Estimamos que la legalidad o ilegalidad de dichas huelgas, en caso que surjan opositores a las mismas, eventualmente puede ser discutida en sede judicial, confrontando esa norma con las restantes que determinan el ejercicio de medidas de acción directa con posterioridad a la instancia de mediación, reguladas en la Ley $\mathrm{N}^{\circ}$ 14.786. Pero por lo menos tendría cabida una discusión al respecto sobre qué norma debe prevalecer.

${ }^{22}$ Ello, sin perjuicio de que la misma ley, en otra disposición -artículo 31-, otorga la exclusividad de negociación colectiva a las asociaciones con personería gremial.

${ }^{23}$ Artículos 5 y 8. 
de la negociación colectiva y el grado de desigualdad de los salarios. La negociación colectiva centralizada de máximo grado tiene efectos homogeneizadores sobre la evolución de los salarios ${ }^{24}$.

En nuestro país, si bien existen sindicatos de empresa, interempresa, de trabajadores transitorios y de trabajadores independientes, los únicos que tienen derecho a la negociación colectiva vinculante son aquellos de empresa, siendo esta absolutamente descentralizada.

\section{Sindicatos de simple inscripción y sindicatos con personería gremial}

Otro aspecto esencial y característico de esta norma es que se distingue entre sindicatos simplemente inscritos y sindicatos con personería gremial. Estos últimos son aquellos que tienen, a lo menos, el $20 \%$ de afiliados considerando la totalidad de trabajadores que se desenvuelven en el sector de que se trate. La ley reserva a estos últimos ciertos derechos sindicales, como defender y representar ante el Estado y los empleadores los intereses individuales y colectivos de los trabajadores e intervenir en negociaciones colectivas ${ }^{25}$.

En este sentido, se ha dicho que "el modelo se basa en un régimen de unicidad, en función del ejercicio de la personería gremial”, que "se opondría al de pluralidad sindical, que se refiere a un sistema en el cual es posible constituir diferentes asociaciones profesionales en cada actividad, profesión u oficio, o bien contar con diversas entidades representativas de los trabajadores" 26 .

En Chile, en cambio, el modelo existente sería el extremo del sistema de pluralidad sindical $^{27}$, pudiendo constituirse diferentes sindicatos inclusive dentro de la misma empresa, y todos ellos con facultades de negociar colectivamente, y además, pudiendo conformarse grupos negociadores sin estar organizados en sindicatos.

Tenemos que señalar que esta disposición, que otorga exclusividad en el ejercicio del derecho a negociación colectiva a los sindicatos con personería gremial, ha sido criticada como atentatoria del principio de libertad sindical por la Organización Internacional del Trabajo, señalándose que en los bechos constituye un disuasivo muy fuerte para que los trabajadores decidan libremente constituir o afiliarse a sindicatos que no gozan de esa personería ${ }^{28}$ y que es incompatible con el Convenio $n^{\circ} 87$ sobre Libertad Sindical y Protección del Derecho de Sindicación.

Radicotti ha reflejado este debate en los términos siguientes: "si bien para algunos la pluralidad ocasionaría la división del movimiento obrero; para otros, su atomización

${ }^{24}$ Marshall A., Perelman, L., "Cambios en los patrones de la negociación colectiva en la Argentina y sus factores explicativos”, en Estudios Sociológicos, mayo-agosto, Colegio de México, Distrito Federal, México, vol. XXII, no 2, 2004, p. 414.

25 Artículo 31. Sin embargo, como veremos más adelante, esta norma tiene ciertas excepciones, ya que hay casos en que se permite negociación colectiva a empresas de ámbito menor.

${ }^{26}$ Radiciotti, L., “¿Democracia sindical en Argentina? Un análisis sobre sus condiciones y posibilidades”, en Trabajo y Sociedad, Santiago del Estero, no 18, junio 2011, p. 255.

27 Íbid.

${ }^{28}$ Bronstain, A., Derecho internacional y comparado del trabajo, Organización Internacional del Trabajo, Ginebra, Suiza, 2010, p. 266. 
y pérdida de poder para alcanzar sus objetivos como sindicatos es la condición para la existencia de un régimen en el cual se respete la libertad sindical" 29.

Nos inscribimos dentro de los primeros. Ello, por cuanto la relación de trabajo es una relación esencialmente desigual, de subordinación o dependencia, en donde una parte -la trabajadora- es sujeto y objeto a la vez de dicha relación ${ }^{30}$. El principio de la libertad sindical no puede entenderse soslayando esta cuestión. En una relación desigual de poder, el ordenamiento jurídico de todo Estado democrático de derecho debe tener normas que podríamos estimar de discriminación positiva, tendientes a dar protección a la parte débil y a contrarrestar la desigualdad entre las personas, en este caso, la desigualdad entre la parte trabajadora y la empleadora ${ }^{31}$. La autocomposición mediante la organización colectiva de los trabajadores y la autonomía colectiva es quizás la forma por excelencia que tienen las legislaciones para abordar esta situación de desigualdad inicial. Palomeque lo señala en términos de poder de autorregulación, de determinación autónoma, de representación de los intereses de clase y de defensa de ellos ${ }^{32}$.

En efecto, estimamos que en condiciones desiguales la fuerza del sindicato y de la negociación está dada por la existencia de un sindicato único que pueda negociar colectivamente -en este caso, el sindicato con personería gremial-en defensa de los intereses comunes del conjunto de los trabajadores -ya que en tanto clase social, tiene intereses comunes-. Y que "la libertad planteada en término abstracto -en un sistema capitalista como el actual- es sinónimo de desigualdad social e injusticia”33.

Una solución intermedia ha sido propuesta por Simón: podría abrirse una puerta a los sindicatos simplemente inscritos para negociar, siempre que lo hagan al alza y que la negociación con un sindicato simplemente inscrito no implique un obstáculo alguno para la que emprenda un sindicato con personería gremial...pudiéndose en algún caso vedar la negociación al sindicato simplemente inscrito de alguna materia, como salarios, que fuera capáz (sic) de generar una competencia irracional ${ }^{34}$.

\section{Homologación y efecto erga homnes}

Por último, destacamos dos instituciones fundamentales e íntimamente relacionadas: la homologación y el efecto erga homnes de los instrumentos suscritos. La primera corresponde a una autorización que concede el Ministerio del Trabajo, Empleo y Seguridad

\footnotetext{
${ }^{29}$ Radiciotti, L., ob. cit., p. 255.
}

${ }^{30}$ Por ello es que existen los principios del Derecho del Trabajo, como el principio de protección, tutelar, o pro operario, y el de la primacía de la realidad.

${ }^{31}$ No nos referiremos acá a la función política que cumple el Derecho del Trabajo, que Manuel Carlos Palomeque describe muy bien en su libro Derecho del Trabajo e Ideología, y que José Luis Ugarte caracteriza como "la función oculta" de Derecho del Trabajo, en su libro El Nuevo Derecho del Trabajo.

32 Tapia, F., Sindicatos en el Derecho Chileno del Trabajo, Santiago de Chile, Ed. LexisNexis. 2007, p. 11.

33 Radiciotti, L., ob. cit., p. 256.

${ }^{34}$ Simón, J., ob. cit., p. 45. 
Social (MTEySS), para que el convenio o acuerdo colectivo del trabajo comience a tener vigencia.

Se ha sostenido que esto implicó la asignación de un importante rol al Estado, que por medio de la homologación se reservó la última palabra en la materia, como si fuese un contratante más en el convenio ${ }^{35}$.

Lo característico es que luego de la homologación, el instrumento será vinculante no solo para las partes que lo suscribieron, sino que para todos los trabajadores y empleadores de la rama o rubro correspondiente, firmantes o no, presentes o futuros. Se trata del efecto erga homnes, que es otro elemento esencial del derecho colectivo de trabajo en Argentina. Este efecto explica que el $83 \%$ de los trabajadores -un porcentaje mucho mayor- regule sus condiciones laborales mediante un convenio o acuerdo colectivo del trabajo, mientras que aquellos afiliados a un asociación de trabajadores corresponden a un porcentaje menor, el $37 \% 36$.

En Chile en cambio, luego de su firma el instrumento colectivo debe ser enviado a la Inspección del Trabajo como un mero trámite registral, mas no como una formalidad para la validez del mismo. En este aspecto, hay un mayor respeto de la libertad sindical que en Argentina. Y será válido únicamente para las partes que lo suscribieron, que además de ser la parte empleadora y los trabajadores sindicalizados, pueden ser aquellos trabajadores que no estando sindicalizados, son adherentes al instrumento. Ergo, existen muchísimo menos trabajadores que regulan sus relaciones laborales mediante instrumentos colectivos que en Argentina.

\section{B) Ley $N^{0} 14.250$ de Convenciones Colectivas de Trabajo}

Promulgada en el año 1953, durante el segundo gobierno de Juan Domingo Perón, hoy se mantiene vigente con algunas modificaciones. El texto oficial está dado por el Decreto $1135 / 04$.

Ámbito de aplicación, ámbito de negociación y contenido

En primer término, se establece que su ámbito de aplicación será a las asociaciones sindicales con personería gremial. Se deja fuera únicamente a los trabajadores de la administración pública y a los trabajadores docentes, debido a que ambos sectores de trabajadores tiene un estatuto especial que regula la materia, las Leyes $\mathrm{N}^{\mathrm{o}} 24.185 \mathrm{y}$ 23.929, respectivamente.

En cuanto al ámbito de la negociación colectiva, este puede ser un convenio nacional, regional o de otro ámbito territorial, convenio intersectorial o marco, un convenio

35 Íbid., p. 38.

36 De acuerdo con las cifras entregadas por el Boletín de Estadísticas Laborales del Ministerio del Trabajo, Empleo y la Seguridad Social de la República Argentina para el año 2011. 
de actividad, un convenio de profesión, oficio o categoría, y un convenio de empresa o grupo de empresas ${ }^{37}$.

Luego, en cuanto al contenido de los convenios, el límite está dado por las disposiciones dictadas en protección del interés general y el orden público. En el mismo sentido, las disposiciones de las convenciones deberán ajustarse a las normas legales que rigen las instituciones del derecho del trabajo, a menos que las cláusulas de la convención relacionadas con cada una de esas instituciones resultaren más favorables a los trabajadores y siempre que no afectaran disposiciones dictadas en protección del interés general ${ }^{38}$. En caso contrario, la autoridad de aplicación (MTEySS) no concederá la homologación al convenio.

Otra característica es que se recoge el principio pro operario, en cuanto a la institución de la norma más favorable: La aplicación de las convenciones colectivas no podrá afectar las condiciones más favorables a los trabajadores, estipuladas en sus contratos individuales de trabajo ${ }^{39}$.

Por último, se norma el efecto erga homnes de los convenios en los siguientes términos: - los convenios- ...regirán respecto de todos los trabajadores de la actividad o de la categoría dentro del ámbito a que estas convenciones se refieran... sin perjuicio de que los trabajadores y los empleadores invistan o no el carácter de afiliados a las respectivas asociaciones signatarias ${ }^{40}$.

En Chile, tanto el ámbito de aplicación como de negociación, y el contenido, son mucho más restringidos. Si bien no existe una diferenciación como en Argentina -sindicatos de simple inscripción y con personería gremial-, los únicos que en términos prácticos están dotados de derecho a negociación son los sindicatos de empresa, en el estrecho margen territorial que le da su propia empresa, y sobre materias exclusivas de sus condiciones de trabajo y de remuneraciones, siendo ilegal una negociación en defensa de sus condiciones de vida en general.

\section{La ultractividad y la articulación}

Se establece también lo que la doctrina ha denominado como ultractividad $^{41}$, cuya consecuencia es la aplicabilidad de las cláusulas contenidas en los convenios o acuerdos colectivos de trabajo ${ }^{42}$ con posterioridad a la fecha de término de la vigencia de dichos instrumentos, hasta que una nueva convención colectiva la sustituya.

Y si bien es cierto que las asociaciones con personería gremial son las únicas que por ley pueden negociar colectivamente, sin perjuicio de ello, se establecen normas de articulación entre unidades de negociación de distintos niveles, en que una unidad

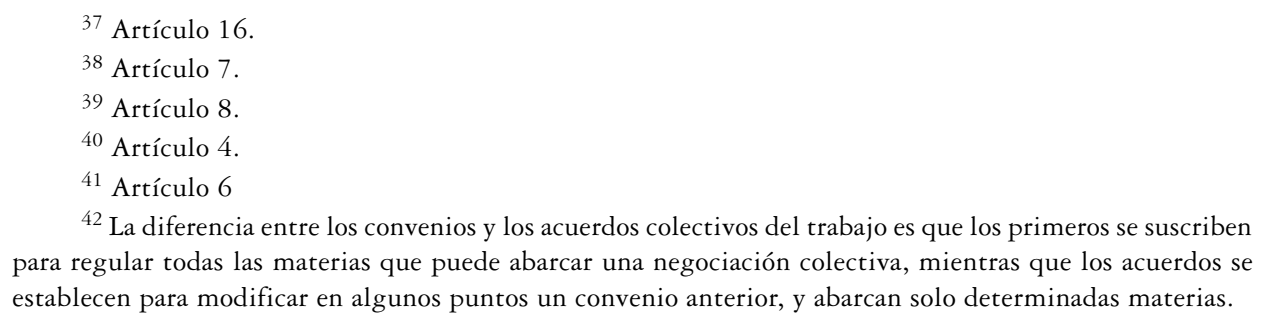

${ }^{42}$ La diferencia entre los convenios y los acuerdos colectivos del trabajo es que los primeros se suscriben para regular todas las materias que puede abarcar una negociación colectiva, mientras que los acuerdos se establecen para modificar en algunos puntos un convenio anterior, y abarcan solo determinadas materias. 
inferior puede negociar colectivamente las siguientes materias: materias delegadas por un convenio colectivo de ámbito superior, materias no tratadas por este, materias propias de la empresa, y condiciones más favorables al trabajador ${ }^{43}$.

Como vemos, constituyen normas en que se recoge -de manera implícita y expresamente-, el principio protector, tutelar o prooperario de la condición más beneficiosa.

Hay que destacar que la articulación resulta sumamente importante para darle dinamismo a la negociación, y para poder negociar en ámbitos más específicos que no sean abordados en los convenios de ámbito superior. En efecto, Etchemendy, en un estudio de la OIT, analizando la negociación colectiva en Argentina desde el año 2003 al 2010 constata lo siguiente: se remarca que la vitalidad de la misma no se ubica solamente en la recuperación de los convenios de actividad, sino que también se refleja en un gran dinamismo de la negociación por empresa... En otras palabras, la negociación colectiva en Argentina, lejos de estar 'congelada' en los grandes convenios que más se publicitan en los medios periodísticos, muestra una multiplicidad y riqueza que permite, en el marco de los grandes pisos que marcan los convenios sectoriales y el salario mínimo negociado a nivel nacional, atender las necesidades de sectores y localidades, trabajadores y empresas específicas ${ }^{44}$.

La ultractividad podría en cierto sentido asimilarse en Chile al "contrato forzoso" que regula el artículo 348 del Código del Trabajo. Sin embargo, esta institución obedece a otro propósito, ya que además de regir únicamente a los trabajadores que suscriban el instrumento, establece un período muy extenso en que no se podrá negociar colectivamente, lo que atenta contra la libertad sindical, y excluye del contrato la reajustabilidad salarial -que es fundamental para los trabajadores-, y los derechos que puedan ejecutarse colectivamente.

\section{Facultades del Ministerio del Trabajo, Empleo y Seguridad Social ${ }^{45}$}

El Ministerio del Trabajo tiene importantes atribuciones. Además de ser la autoridad de aplicación ${ }^{46}$ que otorga la personería gremial y realiza el acto homologatorio, está facultado para extender la obligatoriedad de una convención colectiva a zonas no comprendidas originalmente, por la sola petición de alguna de las partes, y por expreso mandato legal, debe vigilar el cumplimiento de dichos instrumentos ${ }^{47}$.

Se norma que los convenios pueden establecer la conformación de comisiones paritarias, que funcionarán en conformidad a lo señalado por sus estatutos, y además

43 Artículo 18.

${ }^{44}$ Etchemendy, S., El Diálogo Social y las Relaciones Laborales en Argentina 2003-2010. Estado, sindicatos y empresarios en perspectiva comparada, Oficina Regional para América Latina y el Caribe, Programa Regional para la Promoción del Diálogo y la Cohesión Social en América Latina, 1a ed., Buenos Aires, 2011, p. 17.

45 Abreviado con las siglas MTEySS.

${ }^{46}$ Su símil en Chile es la Inspección del Trabajo, que es un órgano descentralizado sujeto a supervigilancia del Ministerio del Trabajo, que debe interpretar y fiscalizar el cumplimiento de los instrumentos suscritos. Sin embargo, no posee tan sólidas atribuciones. No existe acto homologatorio, y no tiene potestades para extender el instrumento a otros sectores o a otros trabajadores.

${ }^{47}$ Artículo 12. 
tendrán facultades de interpretación de la convención, e intervención en controversias individuales o pluriindividuales surgidas por aplicación de la convención, entre otras funciones $^{48}$. Y en caso que el convenio no prevea su conformación, se permite de todos modos crear una comisión paritaria, la que junto a representantes de los trabajadores y empleadores, se integrará por un miembro del Ministerio del Trabajo, quien será el encargado de presidirla, con facultades de interpretación del instrumento colectivo.

Por último, identificamos en que este modelo han influido determinantes políticoideológicos ${ }^{49}$, en cuanto a que la negociación colectiva refleja la orientación de las políticas del gobierno de Perón, y asimismo, han influido determinantes jurídico-institucionales, ya que en este caso, los marcos institucionales fuertes favorecen y facilitan la negociación centralizada 50 .

\section{C) Ley $N^{o} 23.546$ sobre Procedimientos de la Negociación Colectiva}

Esta normativa se dicta en el año 1988, durante el gobierno de Raúl Alfonsín. Establece un procedimiento simple, obligatorio, que incorpora el principio de buena fe, incorpora procedimientos especiales preventivos de crisis, y en empresas concursadas.

En síntesis, consiste en que la unidad de negociación de la asociación de trabajadores comunica al empleador o asociación de empleadores un proyecto de convenio o de acuerdo, indicándole las personas, la materia, y el territorio que cubrirá el instrumento, con obligatoriedad para el empleador -o asociación de empleadores- de dar una respuesta. En un plazo de 15 días se debe conformar la comisión negociadora con representantes de ambas partes. No se señala un período máximo para realizar la negociación, sino que únicamente se estatuye: el deber de negociar bajo apercibimiento de elevadas multas ${ }^{51}$, hacerlo de buena fe, tratándose de negociación de empresa se señala información específica que es deber intercambiar el acto homologatorio del instrumento, y que en caso de conflicto se aplicará la Ley $\mathrm{N}^{\circ} 14.786$. Sin perjuicio de ello, las partes de común acuerdo pueden someterse a la intervención de un servicio de mediación, conciliación y arbitraje que funciona en el Ministerio del Trabajo, Empleo y Seguridad Social.

En procedimientos de crisis, se señala una serie de materias sobre las que es obligatorio para la empresa informar, entre las que destacamos, mantenimiento del empleo, movilidad funcional, horaria, o salarial, innovación tecnológica y cambio organizacional,

${ }^{48}$ Artículos 13 y 14.

49 Senén, C., Medwid, B. y Trajtemberg D., "La negociación colectiva y sus determinantes en la Argentina. Un abordaje desde los debates de las relaciones laborales”. [En Línea] Revista Latinoamericana de Estudios del Trabajo, Año16, n 25, 2011, p. 174 <http://relet.iesp.uerj.br/Relet_25/155.pdf > [consulta: 6 de julio 2012]

${ }^{50}$ Frege y Kelly, citadas en Senén, C., et.al, ob. cit., p. 175.

${ }^{51} \mathrm{La}$ acción se debe interponer ante el Tribunal del Trabajo competente, mediante el procedimiento sumarísimo contemplado en el artículo 498 del Código Procesal Civil y Comercial de la Nación -o su equivalente de los Códigos Procesales Civiles provinciales-, y la multa ascenderá al monto correspondiente al $20 \%$ del total de la masa salarial. Se incrementará en $5 \%$ por cada cinco días de retraso de la parte empleadora en iniciar las negociaciones, y podrá aumentarse hasta en $100 \%$ de la masa salarial en caso de reincidencia en dicha conducta con posterioridad. 
recalificación y formación profesional de los trabajadores, reubicación interna o externa de trabajadores, programas de reinserción laboral, y programas de apoyo a la generación de microemprendimientos para los trabajadores afectados.

En procedimientos en empresas concursadas, será obligatorio al empleador informar especialmente sobre las siguientes materias: causas de la crisis y sus repercusiones sobre el empleo, situación económico-financiera de la empresa y del entorno en que se desenvuelve, propuestas de acuerdo que haya con los acreedores, mecanismos de rehabilitación de la actividad productiva, y situación de los créditos laborales.

En Chile, como se ha dicho, se norma detalladamente el procedimiento de negociación colectiva reglada, estableciéndose una serie de plazos y etapas, sin existir normas especiales protectoras del trabajador para casos de crisis o de empresas concursadas.

\section{D) Ley $N^{\circ} 14.786$, sobre Resolución de Conflictos Colectivos del Trabajo ${ }^{52}$}

En caso que fracase la negociación colectiva, esta normativa prescribe una instancia de conciliación obligatoria antes de adoptar medidas de acción directa. Se realiza ante autoridad administrativa (MTEySS), y consiste en una o más audiencias de mediación, luego de las cuales, si no hay avenimiento entre las partes, la autoridad emite una "fórmula conciliatoria". Existirán tres posibilidades: se puede considerar esta fórmula conciliatoria y llegar a un acuerdo entre las partes, o bien, ellas deciden voluntariamente someter el asunto a arbitraje -y dictarse finalmente un laudo arbitral vinculante para las partes del mismo modo en que lo es un convenio colectivo de trabajo-, o, en tercer lugar, pueden tomar medidas de acción directa. La mediación y el arbitraje, si lo hubiese, deben realizarse en un breve plazo de 15 días -que pueden extenderse a 20 días-, contados desde que se da inicio a la mediación. En caso que se decida tomar medidas de acción directa, la autoridad mediadora emitirá un informe donde constatará las causas del conflicto, un resumen de las negociaciones, la fórmula de conciliación propuesta, la parte que la propuso, quién la aceptó, quién la rechazó.

Es importante destacar que, luego del fracaso de la conciliación, las partes pueden adoptar las medidas de acción directa que estimen. Entre ellas, se otorga la posibilidad a la parte empleadora de adoptar la medida de cierre del establecimiento o lock out, y a la trabajadora, de ejercer la huelga. Y en relación con la figura de contratación de trabajadores de reemplazo o rompehuelgas, si bien no se señala en términos explícitos, no está permitida. En efecto, en caso que ello ocurriera, los trabajadores pueden ejercer diversas acciones judiciales tales como una acción por despido discriminatorio, o por práctica desleal del empleador, una tutela de derechos, o bien, una acción o recurso de amparo, todas las cuales deben ejercerse ante el Tribunal del Trabajo competente.

En Chile hay ciertas similitudes, ya que luego del fracaso de la negociación colectiva se pueden tomar medidas de acción directa, y hacer efectiva la huelga, y además

52 Sancionada el 22 de diciembre de 1958. Esta ley no se aplica a conflictos suscitados en que estén involucrados trabajadores a domicilio, ni tampoco a trabajadores rurales, que se rigen por la Ley $\mathrm{N}^{\circ} 12.713$ y por la Ley $\mathrm{N}^{\mathrm{o}} 13.020$, respectivamente. 
se reglamentan las instancias de mediación, arbitraje y buenos oficios que se realizan ante la Inspección del Trabajo. Sin embargo, difieren en que acá estas últimas son de carácter voluntario.

\section{E) Ley $N^{\circ} 25.877$ de Ordenamiento del Régimen Laboral}

Esta ley se dicta con el objeto de derogar la Ley $\mathrm{N}^{0} 25.250$ que había sido promulgada en el año 2000, durante los gobiernos de corte neoliberal, que -siguiendo la política económica del consenso de Washington- mediante dicha norma habían suprimido una serie de derechos individuales, colectivos y de la seguridad social. Entre ellos, la norma había modificado la Ley $\mathrm{N}^{\circ} 14.250$ de Convenciones Colectivas de Trabajo, la Ley $\mathrm{N}^{\circ} 23.546$ sobre Procedimientos de la Negociación Colectiva, y la Ley $\mathrm{N}^{\mathrm{o}} 14.786$ de Conflictos Colectivos de Trabajo. Con la promulgación de la Ley N $\mathrm{N}^{\circ} 25.877$ en el año 2004 se restablecen tales derechos colectivos, que hemos visto en los apartados anteriores - las asociaciones centralizadas, convenios colectivos del trabajo por rama, efecto erga homnes de los convenios, la ultractividad, la homologación, la determinación del MTEySS como autoridad de aplicación, entre otros-.

$Y$ efectivamente esta reforma tuvo consecuencias positivas, expresadas en los términos siguientes: la Ley $N^{o} 25.877$ ha permitido un renacer de la negociación en todos sus niveles, incluso en el de las empresas que algunos pronosticaban en vías de extinción a partir de las reformas impuestas por la ley $y^{53}$.

Únicamente cabe agregar que esta ley, además de restablecer derechos colectivos, regula la huelga en los servicios esenciales, prescribiendo que cuando por un conflicto de trabajo alguna de las partes decidiera la adopción de medidas legítimas de acción directa que involucren actividades que puedan ser consideradas servicios esenciales, deberá garantizar la prestación de servicios mínimos para evitar su interrupción ${ }^{54}$. Y luego señala los servicios que se consideran esenciales: los servicios sanitarios y hospitalarios, la producción y distribución de agua potable, energía eléctrica y gas y el control del tráfico aéreo.

Estimamos adecuada esta regulación, ya que se ponderan los derechos fundamentales en conflicto -el derecho a huelga por un lado, y derecho a la vida, a la salud, y a la seguridad por el otro-, y se determina una solución en que ninguno de ellos se vea anulado.

La normativa chilena, en cambio, prohíbe la huelga en los servicios esenciales ${ }^{55}$, y asimismo, establece un listado demasiado amplio que tendrá tal calidad, lo que ha sido materia de recomendaciones al Estado de Chile en reiteradas ocasiones por parte de los órganos de control de la OIT $^{56}$.

53 Simón, J., ob. cit., p. 45.

${ }^{54}$ Artículo 24.

${ }^{55}$ La prohibición se encuentra normada en el artículo 384 del Código del Trabajo, y en el artículo 19 $\mathrm{n}^{\circ} 16$ inciso quinto de la Constitución Política de la República de Chile.

${ }^{56}$ Para profundizar en este tema, ver el Informe Anual sobre Derechos Humanos En Chile, 2008, Santiago de Chile, Universidad Diego Portales, pp. 152-155. 


\section{F) Ley $N^{\circ} 25.674$ sobre Cupo Sindical Femenino}

Por último, esta ley -sancionada el 6 de noviembre de 2002- establece una participación obligatoria de mujeres en los cargos directivos y en las unidades de negociación colectiva, la que no debe ser inferior al $30 \%$ del total de trabajadores de dicha rama o actividad $^{57}$. Si el total de mujeres fuese inferior a ese porcentaje, entonces su participación será la más alta posible considerando la cantidad de mujeres que trabaja en dicha rama, empresa, actividad o sector.

En caso de suscribirse un instrumento sin la participación de mujeres que corresponde en conformidad a la ley, la sanción será la inoponibilidad del instrumento para las mujeres, salvo en los casos en que se fijen condiciones más beneficiosas que las existentes ${ }^{58}$.

Sin duda, esta ley es un avance en materia de igualdad de género. Chile no tiene una norma similar. Sin embargo, debemos mencionar una crítica que la Comisión Tripartita de Igualdad de Trato y Oportunidades entre Varones y Mujeres en el Mundo Laboral ha formulado, refiriéndose a la sanción que se establece en caso de incumplimiento: Se está suponiendo que la burla del cupo femenino no resulta causal de nulidad del convenio y que es válido respecto de los trabajadores varones del sector y las mujeres que no hagan valer la inoponibilidad del acuerdo, y que se supone la factibilidad de que el convenio sea aplicado a los hombres y no a las mujeres 59 .

En efecto, se cuestiona que la sanción no sea la nulidad del convenio, ya que de todos modos será aplicable para los hombres, e incluso para las mujeres que no reclamen la inoponibilidad en sede judicial.

\section{CONCLusiones}

En Argentina la población que ejerce sus Derechos Fundamentales Colectivos del Trabajo es significativa, y a la vez existe un marco jurídico proteccionista de tales derechos, tanto a nivel legal como constitucional, diverso de lo que ocurre en Chile.

Los derechos de sindicación, de negociación colectiva y de huelga se encuentran garantizados a nivel constitucional. La huelga no tiene una regulación específica, salvo una limitación tratándose de la huelga en los servicios esenciales, correspondiéndose con el modelo más respetuoso de la autonomía colectiva, el modelo autónomo de huelga.

De acuerdo con la Constitución Nacional de la República Argentina, se ha adoptado un sistema monista ${ }^{60}$, en que el Derecho Internacional y el Nacional se consideran parte de la misma esfera jurídica. En efecto, la norma, el convenio o tratado internacional pueden ser invocados directamente por el juez nacional -de diversas maneras-,

\footnotetext{
57 Artículos 1 y 3.

58 Artículo 2.

59 Comisión Tripartita de Igualdad de Trato y Oportunidades entre Varones y Mujeres en el Mundo Laboral, "Ley de cupo sindical femenino 25.674 y Decreto Complementario 514/2003".

${ }^{60}$ En relación con el Derecho Internacional del Trabajo que verse sobre Derechos Humanos.
} 
independientemente de haberse dictado una ley sobre la materia, lo que es de suma importancia, considerando que Argentina ha ratificado todos los convenios de la OIT sobre Derecho Colectivo del Trabajo.

Se estableció que la estructura sindical se caracteriza por tener un sistema de duplicidad de sindicatos -asociaciones sindicales simplemente inscritas y aquellas con personería gremial-, reservándose una serie de derechos a éstas últimas, entre los que se destaca el derecho a negociar colectivamente.

En cuanto a la negociación colectiva, advertimos que esta puede ser de diversos niveles: descentralizada -al nivel de empresa-, centralizada de nivel intermedio -por actividad o rama de actividad-, o centralizada, predominando la negociación por rama. Y que se promueven las negociaciones de ámbito mayor, con un sistema de articulación a negociaciones de ámbito menor. Además, se avanza en materia de equidad de género al prescribir un porcentaje obligatorio de participación de mujeres.

Los convenios o acuerdos colectivos del trabajo rigen tanto para los trabajadores afiliados como para los que no lo están, con garantía de ultractividad, recogiéndose el principio protector en diversas disposiciones en que prevalece la cláusula más beneficiosa para el trabajador.

Cabe destacar la permanente presencia e intervención del Estado -específicamente, del Ministerio del Trabajo, Empleo y Seguridad Social que corresponde a la autoridad de aplicación-, en distintas instancias: en el otorgamiento de personería gremial, en la homologación de los convenios, en la fiscalización de su efectivo cumplimiento, como integrante que preside las comisiones paritarias, y como mediador en el procedimiento de conflictos del trabajo, entre otras potestades.

Las principales críticas al modelo argentino apuntan al sistema de duplicidad de sindicatos -por estimarse que se favorece la figura del "monopolio sindical", atentándose contra la libertad sindical-, y a la excesiva injerencia del Estado en materias propias de las organizaciones sindicales. En relación con la primera, no la compartimos, coincidiendo con Radicotti, en cuanto a que la libertad planteada en término abstracto -en un sistema capitalista como el actual-es sinónimo de desigualdad social e injusticia ${ }^{61}$. Acogemos sobre todo la segunda crítica, en el sentido de que consideramos necesario velar por la independencia sindical como parte integrante de la autonomía colectiva, atributo esencial de la libertad sindical. Ello, sin perjuicio de la existencia de normativas indispensables -y que todo Estado debe tener- para la organización y el funcionamiento de las asociaciones sindicales.

Por último, analizando el modelo argentino, es posible identificar concretamente ciertas tareas pendientes para el fortalecimiento del Derecho Colectivo del Trabajo en Chile, que se han puesto ya sobre la mesa con anterioridad: consagrar, dentro del catálogo de Derechos Fundamentales contemplado en el artículo 19 de la Constitución Política de la República, el derecho a huelga y otorgarle la correspondiente protección constitucional, fortalecer la negociación colectiva, incluyéndose a diversos sectores hoy

${ }^{61}$ Radiciotti, L., ob. cit., p. 256. 
excluidos, estableciéndose la obligatoriedad de la negociación colectiva reglada a nivel interempresa en el supuesto que los sindicatos interempresa decidan negociar en ese nivel, reformar la norma que prohíbe la huelga en los servicios esenciales, permitiéndose el ejercicio de este derecho con ciertas restricciones, como la prestación de servicios mínimos, ampliar los supuestos en que esté permitida la huelga, no exclusivamente como la última etapa del procedimiento reglado, eliminar la prohibición de la figura del reemplazo de trabajadores en huelga, consagrar normas tendientes a promover la igualdad de género. Ello, con el objetivo de promover el ejercicio de los derechos fundamentales colectivos de los trabajadores chilenos, en beneficio directo de ellos mismos y de las familias que conforman nuestro país.

\section{BIBLIOGRAFÍA}

ANIGSTEIN, Cecilia, "Abordajes sobre la negociación colectiva durante la convertibilidad. Aportes para interrogar al presente" [En Línea], en Trabajo y Sociedad, Santiago del Estero, n 17, dic. 2011, pp. 229-245. <http://www.scielar/scielo.php?pid=S1514-68712011000200016\&script =sci_ arttext $>$ [consulta: 8 de julio 2012]

Beaudonnet, Xavier, Derecho internacional del trabajo y derecho interno, Manual de formación para jueces, juristas y docentes en derecho, Centro Internacional de Formación OIT. Turín, Italia, 2010.

Boletín de Estadísticas Laborales, Ministerio del Trabajo, Empleo y la Seguridad Social [En Línea], en <http://www.trabajo.gov.ar/left/estadisticas/bel/index.asp > [consulta: 10 de julio 2012]

Bronstain, Arturo, Derecho internacional y comparado del trabajo, Organización Internacional del Trabajo, Ginebra, Suiza, 2010.

CaAmaño, Eduardo y Ugarte, José Luis, Negociación Colectiva y Libertad Sindical. Un enfoque crítico, Santiago de Chile, Legalpublishing, 2008.

Comisión Tripartita de Igualdad de Trato y Oportunidades entre Varones y Mujeres en el Mundo Laboral.S/A, Ley de cupo sindical femenino 25.674 y Decreto Complementario 514/2003 [En Línea] < training.itcilo.org/actrav/.../POWER_CUPO_SINDICAL.ppt> [consulta: 23 de julio 2012].

Encuesta Nacional de Condiciones Laborales, Dirección de Trabajo, Chile, 2008.

Eтchemendy, Sebastián, El Diálogo Social y las Relaciones Laborales en Argentina 2003-2010. Estado, sindicatos y empresarios en perspectiva comparada, Oficina Regional para América Latina y el Caribe, Programa Regional para la Promoción del Diálogo y la Cohesión Social en América Latina, $1^{\mathrm{a}}$ ed., Buenos Aires, 2011.

Gamonal, Sergio, Derecho Colectivo del Trabajo, Santiago de Chile, Ed. LexisNexis, 2007.

Informe Anual sobre Derechos Humanos En Chile, Santiago de Chile, Universidad Diego Portales, 2008.

Marshall Adriana, Perelman, Laura, "Cambios en los patrones de la negociación colectiva en la Argentina y sus factores explicativos” [En Línea], en Estudios Sociológicos, mayo-agosto, Colegio de México, Distrito Federal México, vol. XXII, nº 2, 2004, p. 414., en <http:// redalyc.uaemex.mx/src/inicio/ArtPdfRed.jsp?iCve =59806506> [consulta: 6 de julio 2012]

Radiciotti, Luisina, “¿Democracia sindical en Argentina? Un análisis sobre sus condiciones y posibilidades" [En Línea], en Trabajo y Sociedad, Santiago del Estero, nº 18, jun. 2011, p. 255 en $<$ http://www.scielo.org.ar/scielo.php?script=sci_arttext\&pid=S1514-68712012000100016\&ln $\mathrm{g}=\mathrm{pt \& nrm}=$ iso\&tlng $=\mathrm{es}>$ [consulta: 5 de julio 2012] 
Senén G., Cecilia, Medwid Bárbara y Trajtemberg David, "La negociación colectiva y sus determinantes en la Argentina. Un abordaje desde los debates de las relaciones laborales" [En Línea], en Revista Latinoamericana de Estudios del Trabajo, año 16, nº 25, 2011, pp. 155-181 $<$ http://relet.iesp.uerj.br/Relet_25/155.pdf > [consulta: 6 de julio 2012]

Simón, Julio, "Breve informe sobre la negociación colectiva en la República Argentina" [En Línea], en Revista de Trabajo, Buenos Aires, año 2, n 3, julio-diciembre, 2006, pp. 37-45 en <http://www.trabajo.gov.ar/left/estadisticas/descargas/revistaDeTrabajo/2006n03_ revistaDeTrabajo/2006n03_a02_jSimon.pdf > [consulta: 9 de julio 2012].

Palomeque, Manuel Carlos, Derecho del Trabajo e Ideología, $2^{a}$ edición, Madrid, España. Ed. Akal Universitaria, 1984.

TAPIA, Francisco, Sindicatos en el Derecho Chileno del Trabajo, Santiago de Chile, Ed. LexisNexis, 2007.

Leyes

Argentina, Constitución Nacional de la República Argentina, 1994.

Argentina, Ministerio de Trabajo, Empleo y la Seguridad Social, Ley No 23.551 sobre Asociaciones Sindicales de Trabajadores, 1988.

Argentina, Ministerio de Trabajo, Empleo y la Seguridad Social, Ley No 25.674 sobre Cupo Sindical Femenino, 2002.

Argentina, Ministerio de Trabajo, Empleo y la Seguridad Social, Ley No 14.250 de Convenciones Colectivas de Trabajo, 1953.

Argentina, Ministerio de Trabajo, Empleo y la Seguridad Social, Ley N ${ }^{\circ} 23.546$ sobre Procedimientos de la Negociación Colectiva, 1988.

Argentina, Ministerio de Trabajo, Empleo y la Seguridad Social, Ley N ${ }^{\circ} 14.786$, sobre Resolución de Conflictos Colectivos del Trabajo, 1958.

Argentina, Ministerio de Trabajo, Empleo y la Seguridad Social, Ley No 25.877 de Ordenamiento del Régimen Laboral, 2004.

Argentina, Ministerio de Trabajo, Empleo y la Seguridad Social, Ley $\mathrm{N}^{\circ} 23.551$ que ratifica el Convenio $\mathrm{N}^{\circ} 154$ Organización Internacional del Trabajo, 1988.

ChILe, Constitución Política de la República, 1980.

Chile, Código del Trabajo, 2003.

Convención Americana sobre Derechos Humanos, San José, Costa Rica, 1969.

Convenio $N^{\circ} 87$ sobre la libertad sindical y la protección del derecho de Sindicación, Conferencia General de la Organización Internacional del Trabajo, San Francisco, Estados Unidos, 1948.

Convenio N $^{\circ} 98$ sobre el derecho de sindicación y de negociación colectiva, Conferencia General de la Organización Internacional del Trabajo, Ginebra, Suiza, 1949.

Convenio 154 sobre fomento de la negociación colectiva, Conferencia General de la Organización Internacional del Trabajo, 1981.

Declaración Universal de Derechos Humanos, Asamblea General Naciones Unidas, 1948.

DeClaración Americana de los Derechos y Deberes del Hombre, Novena Conferencia Internacional Americana, Bogotá, Colombia, 1948. 